\title{
FIRST AND SECOND THOUGHTS ABOUT TEACHING SECONDARY CHEMISTRY
}

\author{
Georgios Tsaparlis ${ }^{a}$ \\ a Department of Chemistry, University of Ioannina, \\ GR-451 10 Ioannina, Greece. E-mail: gtseper@cc.uoi.gr
}

\begin{abstract}
This paper selectively reviews both early and more recent work by the author on the teaching of chemistry at secondary level. The purpose is twofold: (i) to review the proposals, their features, and the research behind them, (ii) to emphasize the strength over time of the work presented, but also the need for constant revision. The reviewed topics for lower secondary education (7th-9th grades) include: a revised curriculum (1984); a study of Greek students' contextual chemistry knowledge (1987); an updated proposal about the curriculum (2001); an integrated physics and chemistry program for the 7 th grade (2000), that has been further developed recently (2011) to include biology; two research studies on teaching methodology (2000)'; a chemistry course for the $8^{\text {th }}$ grade (2010); revision of the current formal Greek chemistry curriculum (2014). The reviewed topics for upper secondary education (10th-12th grades) include: three early (1981, 1985a, 1985b) studies on Greek students' strengths and difficulties with chemistry; a context-based chemistry curriculum (1988, 1991); proposals for new chemistry curricula $(2000,2011,2014)$ for the $10^{\text {th }}$ and $11^{\text {th }}$ grades. Coupling to the PARSEL modules is also made. The paper concludes by making reference and connection to the work of Hans Jürgen Schmidt.
\end{abstract}

\section{Introduction}

This paper selectively reviews ${ }^{1}$ older and more recent work by the author and his graduate students that relate to lower and upper secondary school chemistry; in particular the studies reviewed concern the following topics: (a) students' difficulties and misconceptions, (b) proposals for curricula, (c) writing of educational material in the form of books. The purpose is twofold:

i. to provide relevant information about the proposals, their features, and the research behind them;

ii. to emphasize the strength over time of the work presented, but also the need for constant revision.

Theories in science education. Piagetian theory was the first cognitive theory that became internal to science education in the late 1970s, in that not only were the students classified into developmental levels, but scientific concepts were also classified as requiring for their understanding either concrete or formal logic (Herron, 1978; Shayer and Adey, (1981). The impact of Piagetian theory on science education was confirmed by a special issue (Vol. 2, Issue 3,1964) of the Journal of Research in Science Teaching that was dedicated to Piaget,

${ }^{1}$ Part of the reviewed work has been published only in Greek. In this case, references to the original publications in Greek are provided. In case of work which has been published in English, only the references in English are supplied. Note that earlier versions of the latter work have also been published previously in Greek, but the relevant references are not quoted here. 
and including a paper by Piaget himself. A central tenant of Piagetian theory, in addition to the developmental levels, was (personal) constructivism, which forwarded the notion that knowledge is constructed actively by the student through a process of cognitive conflicts / disequilibriums and the subsequent equilibration / the accommodation of new concepts. This process is very relevant to what has become important to science educators in recent years, that is, to conceptual change.

Actually, the field of science education diverged somewhat from Piagetian theory in the 1980 s, and focused on the study of alternative conceptions or students' ideas or students' misconceptions. Conceptual change derives from the alternative conceptions movement that has dominated and continues to dominate the field of science education since the 1980 . The alternative conceptions movement is also supported by constructivism. In point of fact, constructivism acquired many forms, beyond Piagetian personal constructivism (Bodner, 2001).

\section{Chemistry in lower secondary education}

In most countries, including Greece, lower secondary education involves three grades (7th, 8th, and 9th) - ages 12-14. The way in which the various science subjects are treated at this level varies: in many countries (e.g. England, Scotland, Ireland, Israel and some states of Germany) an integrated science course exists. ${ }^{2}$ In some countries (e.g. Denmark) a grouping of physics with chemistry occurs or (e.g. France) of biology with geology. Finally, in many countries (e.g. Greece, and German states) the practice of separate subjects prevails.

As the work reviewed in this paper has been carried out in the Greek context, it is necessary to consider chemistry in Greek secondary education. Chemistry in lower secondary Greek scools is taught as a separate subject (and so are physics and biology), in the 8th and the 9th grade for one 45-minute period per week. A Greek peculiarity is that the time allocated to chemistry is only half of that made available for the teaching of physics, biology and geography. ${ }^{3}$

My first education research study (Tsaparlis, 1984a, in Greek) reported a survey of Greek teachers' perception of the difficulty of the various chemistry topics that were covered at the time of the study (the 1980s). The findings confirmed that the stoichiometry topics and concepts (RAM, RMM, mole, molar volume, balancing chemical equations, analogical reasoning in stoichiometric calculations) were seen as the most difficult ones. Other difficult topics for the $8^{\text {th }}$ grade were: the periodic table; ionic and covalent bonds; structural and electronic formulas of covalent compounds; single-atom ions; multi-atom ions; ionic and molecular reactions; simple and double substitution reactions. Piagetian theory was invoked

\footnotetext{
${ }^{2}$ In UK, secondary schools (age 12-16) can either teach biology, physics and chemistry as separate subjects or can teach integrated science. In general, the more academic schools continue to teach the subjects separately but more and more schools seem to have deserted to the integrated approach.

${ }^{3}$ Recently, an extra hour was given to physics, so the time of chemistry is now less than half of that of physics.
} 
for the explanation of the findings. Later, a critical analysis of the concepts of atomic and molecular structure (Tsaparlis, 1997) employed the following perspectives of science education (i) the Piagetian developmental perspective, (ii) the Ausubelian theory of meaningful learning, (iii) the information - processing theory, and (iv) the alternative conceptions movement, and arrived at the same conclusion, which confirmed students' conceptual difficulties about the structural concepts.

Based on the findings of the 1984a study, I made proposals for a revised secondary chemistry curriculum (Tsaparlis, 1984b, 1991a, in Greek), which placed the emphasis on the macroscopic study of various topics, and maintained the concepts of molecule and atom, and of chemical notation but without atomic structure and bonding. In addition, I recommended avoiding complicated reactions without actual relevance to everyday life.

In a subsequent study with beginning $10^{\text {th }}$ grade students (Tsaparlis, $1991 \mathrm{~b}$ and 1994 , in Greek), the various topics tested showed the following percentages of correct responses:

- Symbols of elements (73.5\%)

- Equation balancing (40.7\%)

- Chemical formulas of binary compounds (11.2\%)

- Placing of electrons in shells (10,5\%)

- Number of electrons in ions (13.3\%)

- Ionic and covalent compounds (14.0\%)

- Prediction of reactions (11.0\%)

Two studies on the connection of the taught chemistry with students' everyday life - one on lower-secondary education (Tsaparlis, 1987) the other on upper-secondary education (Tsaparlis, 1991c) revealed very poor knowledge; for instance, 97\% of lower-secondary students ignored the content of a liquefied-gas bottle, $96 \%$ ignored the content of a fire extinguisher, $89 \%$ could not explain what a bleaching liquid was, and $81 \%$ were unsure of what petrol is. In the case of upper-secondary students, $77 \%$ ignored the gas or gases contained in a liquefied gas, $64 \%$ the content of a fire extinguisher, $60 \%$ failed to appreciate that sulfuric acid is the electrolyte in lead batteries, and $57 \%$ that benzoic acid is a common food preservative.

In 1997-98, a new program of studies for Greek lower secondary chemistry was introduced and new textbook packages were written that adopted the proposals of educational research. These were characterized by the complete removal of stoichiometry (Georgiadou et al., 2004). This program retained atoms and molecules, but avoided the details of atomic and molecular structure. An integral part of the new program was the execution of a number of experiments by the students; to this purpose, laboratory manuals were included in the book packages. In 2001, I presented second thoughts of mine about lower secondary chemistry (Tsaparlis, 2001, in Greek). In these, I distinguished the aims of the course into three kinds: (1) aims of theoretical/formal chemistry; (2) aims of practical abilities; (3) aims of chemistry in context. 
Two longitudinal research projects. The doctorate theses of two students of mine dealt with issues of chemistry teaching at the lower secondary level. Both studies were longitudinal (two-year long). In the one study (Zarotiadou and Tsaparlis, 2000), we compared two methods of teaching: a constructivist method (CM), based on Piaget's theory of cognitive development; and a meaningful-receptive method (MRM), based on Ausubel's theory of meaningful learning. It was found that the CM group scored statistically higher in theory in both the 8th and the 9th grades, while in stoichiometric calculations, the superiority of the CM group occurred only in the 9th grade. The effect of developmental level, of gender and of motivational traits was also examined. Finally, the students generally expressed a preference for the $\mathrm{CM}$.

In the second study (Georgiadou and Tsaparlis, 2000), we experimented with a threecycle method, which went separately over the macro, the representational, and the sub-micro levels of chemistry, and concluded that it should be considered seriously as a good method for introductory chemistry. In the macro cycle, which occupied half of the teaching time, the students became familiar with chemical substances and their properties. Central here was the use of experiment, while chemical notation as well as atoms and molecules were not included. Applying the spiral curriculum, the representational cycle covered the same course material, but added chemical formulae and equations. Finally, the submicro cycle brought atoms and molecules into play. Evaluation of the method by end-of-school-year tests as well as by beginning-of-next year repeat of the same tests, showed that the three-cycle method made the largest single positive effect, compared with a traditional control class and a class in which teaching methods proposed by psychologist R. Case were applied.

An integrated science program for the 7 th grade. In Greece, while general science is taught in the $5^{\text {th }}$ and the $6^{\text {th }}$ grades, physics and chemistry are absent from the $7^{\text {th }}$ grade. To overcome this deficiency, I proposed an integrated program of physics and chemistry for the $7^{\text {th }}$ grade. A relevant book (in Greek), which includes experiments, theory, simple knowledge, and more demanding questions was written in collaboration with a colleague (Tsaparlis and Kampourakis, 2000). Basic features were: the spiral curriculum; qualitative treatment of concepts; taking account of student misconceptions; experimental-constructivist teaching and learning; simplicity of phenomena and principles; exclusion of atoms and molecules, of equations, and of graphs; and connection with everyday life. The program went on trial during 1998-99 and 1999-2000 in eleven schools, involving 24 teachers and about 1500 students. In subsequent work, biology lessons were incorporated into each of the ten units of the above book of integrated physics and chemistry (Tatsi and Tsaparlis, 2011, in Greek), and the output was subjected to a preliminary evaluation by experienced education and science experts (Tatsi and Tsaparlis, 2013, in Greek).

A chemistry course for the $\boldsymbol{8}^{\text {th }}$ Grade. Recently, a novel introductory lowersecondary chemistry course (for the $8^{\text {th }}$ grade) that aims at the application of theories of science education, and in particular of conceptual/meaningful learning and of teaching methodology that encourages active and inquiry forms of learning was proposed (Tsaparlis, 
Kolioulis, and Pappa, 2010). The program is made of six units (matter and soil, water, chemical reactions, air, molecules, atoms) that contain twenty-four lessons. Special emphasis is paid to the meaningful introduction of the concepts of molecule and atom; this introduction is delayed until the last two units of the course. A textbook was written and subjected to a preliminary evaluation by four experienced Greek science teachers (Kolioulis and Tsaparlis, 2007, in Greek).

Revision offormal lower-secondary curriculum in Greece. The present author was the coordinator of a committee that worked out a new program of studies for chemistry of the $7^{\text {th }}$ and $8^{\text {th }}$ grades in Greece, within the project "Education and Lifelong Education New School (21 ${ }^{\text {st }}$ Century School)” (Tsaparlis et al., 2014, in Greek). The main aims were: (i) the re-arrangement of the topics and a rational organization of the material in the school books; (ii) the combination of the change of the program of studies with proper educational material (print and electronic). The methodology combines the macroscopic approach with the submicroscopic and the symbolic levels of chemistry, conceptual understanding, inquiry learning, laboratory teaching, and connection with everyday life.

\section{Chemistry in upper secondary education}

As in many countries, upper secondary education in Greece involves three grades (10th, 11th, and 12th) - ages 15-18. The 1oth grade is an orientation year, with common curriculum for all students, while in the 11th and the 12th grades, in addtion to general education subjects, students have to follow one out of three specialized streams. ${ }^{4}$ All three science subjects (physics, chemistry, and biology) are treated as separate courses both as general education subjects, and in the specialized streams of study.

Three early studies identified Greek students' strengths and difficulties with chemistry, based on testing beginning first-year chemistry students (Tsaparlis, 1981, 1985a, 1985b). The 1985b study used the findings of the 1981 and 1985a studies to identify some of the main difficulties of chemistry in upper secondary school (lykeion). Difficulties were detected about: the naming of compounds and the writing of chemical formulas; ionic and covalent compounds; polar and non-polar compounds; ionic and molecular reactions; oxidation numbers $(n=121)$.

Of special interest was the topic of chemical equilibrium $(n=85)$. In a question that asked for the expression of the chemical equilibrium constant $K$ for the equilibrium reaction $\mathrm{N}_{2}+$ $3 \mathrm{H}_{2} \rightleftharpoons{ }_{2} \mathrm{NH}_{3}, 70.1 \%$ of the students gave the correct answer, while $5.7 \%$ wrote the reverse expression $(1 / K)$, and $4.6 \%$ each wrote $\left(2 \mathrm{NH}_{3}\right)^{2} /\left(\mathrm{N}_{2}\right)\left(3 \mathrm{H}_{2}\right)^{3}$ and $\left(\mathrm{NH}_{3}\right)^{2} /(\mathrm{N})(\mathrm{H})^{3}$. The application of the Le Chatelier principle on the effect of increase of temperature on the yield of the same reaction (given the thermochemical equation $\mathrm{N}_{2}+3 \mathrm{H}_{2} \rightleftharpoons{ }_{2} \mathrm{NH}_{3}+22$ kcal) resulted in $82.4 \%$ correct answers, while $14.1 \%$ of the students predicted wrongly that the yield would increase. On the other hand, the correct answers dropped to $45.9 \%$ when the

\footnotetext{
${ }^{4}$ A reform of the upper secondary program in Greece, which contains differences from the previous courses, is currently being introduced.
} 
effect of an increase of temperature on the rate of the same reaction $\left(\mathrm{N}_{2}+3 \mathrm{H}_{2} \longrightarrow 2 \mathrm{NH}_{3}\right)$ was investigated, with $48.2 \%$ of students providing wrong answers: no effect: $37.6 \%$; decrease of rate: $10.6 \%$.

A misconception was seen to be at work here:

Le Chatelier's principle was being applied to reaction rate, when actually it could only be used to predict the direction of a reaction.

In the Anglophone literature, this misconception was reported in a study by Banerjee (1991), according to which students reasoned that when the temperature is increased in an exothermic reaction, the rate of the forward reaction decreases (see also Sozbilir, Pinarbasi, and Canpolatm, 2010).

The topic of ionic equilibria is causing considerable difficulty to many students:

- Asked if $\mathrm{HCO}_{3}{ }^{-}(\mathrm{aq})$ is an acid, a base, or an ampholyte, only $5.9 \%$ of students ( $n=$ 85) provided the correct answer (ampholyte), while $44.7 \%$ did not respond, and 49.4\% gave wrong answers (29.4: acid; 18.8\%: base).

- Asked about the acidity of an aqueous solution of $\mathrm{NH}_{4} \mathrm{Cl}$ (acidic, basic or neutral solution), 31.8\% of students gave the correct answer (acidic), while 11.8\% did not respond, and 56.5\% gave wrong answers (29.4\%: basic; $27.1 \%$ : neutral)

Prediction of the products of inorganic reactions revealed erroneous thinking by a relatively small number of students, who assumed that as long as the products of a reaction are legitimate substances, then the resulting reaction is acceptable (it can actually occur), as the following results demonstrate $(n=127)$ :

- $\quad 2 \mathrm{NaCl}+\mathrm{H}_{2} \mathrm{SO}_{4} \rightarrow \mathrm{H}_{2}+\mathrm{Cl}_{2}+\mathrm{Na}_{2} \mathrm{SO}_{4}(5.9 \%)$

- $\mathrm{Cl}_{2}+\mathrm{SO}_{2} \rightarrow \mathrm{SCl}_{2}+\mathrm{O}_{2}(3.5 \%)$

Note that the above equations are balanced correctly.

Problems were also detected with the writing of chemical formulas, e.g.: $\mathrm{ZnCl}(15.3 \%) \mathrm{MnCl}$ (4.7\%)

The states-of-matter approach (SOMA) and a context-based approach to upper secondary chemistry. Within a project for revising the upper secondary curricula in Greece, the present author as member of a special committee contributed to the proposal of a chemistry program for all students in the $10^{\text {th }}$ and $11^{\text {th }}$ grades. For the $10^{\text {th }}$ grade, chemistry was introduced through the separate study of the three states of matter [the statesof-matter approach (SOMA)] (Tsaparlis, 2000). There are three major units in the program, namely: Air, gases, and the gaseous state; Salt, salts, and the solid state; Water, liquids, and the liquid state. A relevant book was written, which was then submitted to a preliminary evaluation by teachers (Tsaparlis and Pyrgas, 2011).

For the $11^{\text {th }}$ grade, the program moved into the connection of chemistry with life and its applications. As part of another master's thesis, a book has recently been written which covers the $11^{\text {th }}$ grade chemistry (Tsaparlis and Stergiou, 2014, in Greek). The material is based on the above program of studies, and specifically on the connection of chemistry with life and applications. The material is divided into three major units: A: Organic chemistry (with four 
chapters: one on fossil fuels, two chapters on basic organic chemistry, and one chapter on polymers, plastics, and modern materials; b: Chemistry and our life (three chapters, one on drugs, one on foods and nutrition, and one on biomolecules); and c: Chemistry and energy (two chapters, one on electrochemical energy and one on nuclear energy and renewable forms of energy). The $11^{\text {th }}$ grade course, was influenced greatly by one of the first books to adopt a contextual approach to chemistry (Sherman and Sherman, 1983),

\section{Coupling of secondary chemistry to the PARSEL modules}

Chemistry, as a secondary school subject for all, should aim to provide students with chemical literacy and chemical culture, to develop higher-order cognitive skills, and to be a useful, interesting, and enjoyable subject (Tsaparlis, 2000). As such it should target at both the cognitive and the affective domains. Within the affective domain, the current trend is towards a contextual approach to teaching and learning. PARSEL ${ }^{5}$ is a project which has produced educational materials that are available free of charge on the Internet, at: http://www.parsel.uni-kiel.de/cms/. They aim to promote scientific literacy and to enhance popularity and relevance of science teaching and learning. The materials in the form of modules (e.g. Growing plants: does the soil matter?; Milk: keep refrigerated; Should vegetable oil be used as fuel?) cover a range of student levels (Grade 7 upwards) and science subjects. The materials have been developed by a consortium involving eight European Universities (from Estonia, Denmark, Germany (2), Greece, Israel, Portugal and Sweden) and the International Council of Associations for Science Education (UK).

\section{Reference and connection to Hans Jürgen Schmidt's work}

The present contribution was part of a symposium at the ECRICE2O14 conference dedicated to the memory of Professor Hans Jürgen Schmidt. It is imperative then to connect the reviewed work of mine to the work of Schmidt. The major part of Hans Jürgen's work was guided by the alternative conceptions movement. I will focus here on three monumental Schmidt papers (Schmidt, 1991, 1997, 1998). According to Schmidt, "students often make mistakes as they are misled by alternative conceptions because of shift of meaning of some chemical terms. ... Such terms are ambiguous since they contain an old and a new aspect”. For instance:

- Neutralization: a reaction between an acid and a base which consume each other.

- Oxidation has shifted from an oxygen transfer to an electron transfer reaction.

- A chemical reaction was seen as proceeding in one direction, while in principle all chemical reactions reach equilibrium as a result of a forward and a reverse reaction

- The periodic table has developed from a table of elements as substances to a periodic table of atoms of the elements.

Schmidt's concern is reflected in the following question that I often set in the examination of my undergraduate course in chemistry education at the University of Ioannina:

\footnotetext{
${ }^{5}$ Popularity And Relevance of Science Education for scientific Literacy.
} 
The standard (Greek) chemistry textbook for the $9^{\text {th }}$ grade defines a neutralization reaction as the reaction between an acid and a base, which results in a neutral solution $(\mathrm{pH}=7)$. Comment on this statement from the scientific and the education points of view.

In addition, Schmidt was concerned a lot about the aim of the high school chemistry courses: Chemistry is an experimental and an intellectual science. We need courses which are more intellectually challenging...A new teaching culture...(in which) teachers are interested in what students think... (Schmidt, 2000).

In the year 1988, during a Greek conference, influenced greatly by the Sherman and Sherman (1983) contextual approach to chemistry, I made a presentation about "chemistry and tomorrow's citizens", about "chemistry as a general education subject at the threshold of the 21th century". The following were my concluding comments in my 1988 presentation:

We live in a chemical world...(where) a general public, ... adopts an attitude hostile to chemistry, (where) people are scared by the word 'chemistry'... It is a necessity that this public ... considers critically the chemical view of life, (and) the capabilities and the problems of chemistry. (In this way), chemistry will become an interesting, practical, useful subject, in one word, a most urgent subject.

\section{Acknowledgements}

The author wishes to thank Dr Bill Byers for reading this manuscript and making many comments that contributed to its improvement. 


\section{References}

\section{In English}

Banerjee (1991). Misconceptions of students and teachers in chemical equilibrium. International Journal of Science Education, 13(4), 487-494.

Bodner G. (2001). The many forms of constructivism. Journal of Chemical Education, 78, 1107.

Georgiadou A. and Tsaparlis G. (2000). Chemistry teaching in lower secondary school with methods based on: a) psychological theories; b) the macro, representational, and submicro levels of chemistry. Chemistry Education Research and Practice,1, 277-289.

Herron, J. D. (1978). Piaget in the classroom. Journal of Chemical Education, 55, 165-170.

Schmidt H-J. (1991). A label as a hidden persuader: Chemists' neutralisation concept. International Journal of Science Education, 13, 459-471.

Schmidt H-J. (1997). Students' misconceptions - looking for a pattern. Science Education, 81, 123137.

Schmidt H-J. 1998). Does the periodic table refer to chemical elements? School Science Review, $80(290), 71-74$.

Schmidt H-J. (2000). Should chemistry lessons be more intellectually challenging? Chemistry Education Research and Practice, 1, 17-26

Shayer M. \& Adey P. (1981). Toward a science of science teaching. London: Heinman.

Sherman A. \& Sherman S. J. (1983). Chemistry and our changing world. New Jersey: Prentice-Hall.

Sozbilir M., Pinarbasi T., and Canpolatm N. (2010)* Prospective Chemistry Teachers' Conceptions of ChemicalThermodynamics and Kinetics Eurasia Journal of Mathematics, Science \& Technology Education, 2010, 6(2), 111-120.

Tsaparlis G. (1997). Atomic and molecular structure in chemical education: A critical analysis from various perspectives of science education Journal of Chemical Education, 74, 922-925.

Tsaparlis (2000). The States-Of-Matter Approach (SOMA) to high-school chemistry. Chemistry Education Research and Practice, 1, 161-168]

Tsaparlis G.\& Kampourakis C. (2000) . An integrated physics and chemistry program for the 7 th grade. Chemistry Education Research and Practice, 1, 281-294.

Tsaparlis, G., Kolioulis, D., and Pappa, E. (2010). Lower-secondary introductory chemistry course: A novel approach based on science-education theories, with emphasis on the macroscopic approach, and the delayed meaningful teaching of the concepts of molecule and atom. (plus Supplementary Information)

Tsaparlis G. and Pyrgas E. (2011). The states-of-matter approach (soma) to high-school chemistry : textbook and evaluation by teachers: Textbook and evaluation by teachers ESERA e-Proceedings, Strand 4. Lyon, France. http://www.esera.org/publications/eseraconference-proceedings/science-learning-and-citizenship/strand-4/

Zarotiadou, E. and Tsaparlis, G. (2000). Teaching lower-secondary chemistry with a Piagetian constructivist and an Ausbelian meaningful-receptive method: a longitudinal comparison. Chemistry Education Research and Practice, 1, 37-50.

\section{In Greek}

Georgiadou T., Kafetzopoulos K., Provis N., Spyrellis N., and Chiniades D., (2004). Chemistry for the (Greek) eighth grade. Athens: OEDB.

Kolioulis D. and Tsaparlis G. (2007). Eighth-grade chemistry, with emphasis on the macroscopic approach, and the meaningful inttoduction of the concepts of molecule and atom - Textbook and preliminary evaluation by teachers. Proceedings of $5^{\text {th }}$ Greek Conference on science education and new technologies in education, Part 2, pp. 680-689. Ioannina, Greece: KoDiPhEET. 
http://kodipheet.chem.uoi.gr/fifth_conf/pdf_synedriou/teyxos_B/3_didakt_didask_x hm/4_XHM-14telikiF.pdf

Tatsi A. and Tsaparlis G. (2011). Restructuring of lower-secondary biology on the basis of instructional integration and coordination of the science subjects - Textbook of introductory science for the $7^{\text {th }}$ grade, Proceedings of $7^{\text {th }}$ Greek Conference on science education and new technologies in education, pp. 92-101. Alexandroupolis, Greece: ENEPhEET.

http://www.enephet.gr/index.php?page=proceedings-conference\&proceeding_conference_id=8

Tatsi A. and Tsaparlis G. (2013). In corporation of biology lessons in an introductory physical science textbook for the $7^{\text {th }}$ grade: Evaluatiuon by specialists in education and in science. Proceedings of $8^{\text {th }}$ Greek Conference on science education and new technologies in education, pp. 690-700. Volos, Greece: ENEPhEET. http://www.enephet.gr/index.php?page=proceedingsconference\&proceeding_conference_id=9

Tsaparlis G. (1981). Comparative study of the chemical knowledge of new (Greek) chemistry students according to two tertiary entrance examination systems. Chimica Chronica, 46 (14) 40-45.

Tsaparlis G. (1984a). Chemistry in (Greek) lower secondary school (gymnasion) Part A' : Teachers' opinions. Logos \& Praxis, Issue No. 22, 78-96 (plus corrections, Issue No. 23-24).

Tsaparlis G. (1984b). Chemistry in (Greek) lower secondary school (gymnasion) - Part B' : Contribution to a reform of the program of studies. Logos \& Praxis, Issue No. 23-24, 138-143.

Tsaparlis G. (1985a). Tertiary entrance examinations and chemistry: Comparison with previous (Greek) examination systems.Synchroni Ekpaideusi, Issue No. 21, 69-76.

Tsaparlis G. (1985b). Some of the difficulties of chemistry at (Greek) upper secondary school (lykeion). Synchroni Ekpaideusi, Issue No. 24, 40-48.

Tsaparlis G. (1987). Chemistry and life in (Greek) secondary education - Part A, Chemistry and life in lower-secondary school (Gymnasion). Nea Paideia, Issue 44, 152-163.

Tsaparlis G. (1988a). Chemistry and tomorrows citizens - Chemistry as a general education subject at the threshold of the 21th century. Proceedings of $12^{\text {th }}$ Panhellenic Chemistry Conference, pp. 16. Thessaloniki, Greece: Association of Greek Chemists and Aristotle University of Thessaloniki.

Tsaparlis G. (1988b). Teaching the concept of molecule and atom at the $8^{\text {th }}$ grade.

Tsaparlis G. (1991a). Topics of teaching secondary physics and chemistry, $2^{\text {nd }}$ edn., pp. 242-248. Athens, Greece: Grigoris Publications. (1 ${ }^{\text {st }}$ edn. Ioannina, University of Ioannina, 1989)

Tsaparlis (1991b). Chemistry and life in (Greek) secondary education - Part B, Chemistry and life in upper-secondary school (lykeion). Nea Paideia, Issue 44, 161-174.

Tsaparlis (1991c). SOS from lower-secondary chemistry. Chimica Chronica, 53 (4) 111. $2^{\text {nd }}$ edn., pp. 242-248.

Tsaparlis G. (2001). First and second thoughts about teaching (Greek) lower secondary chemistry. In: Teaching of science at the beginning of $21^{\text {st }}$ century: Problems and perspectives, Kokkotas P. (ed.), pp. 93-104. Athens, Greece: Grigoris Publications.

Tsaparlis (1994). SOS from lower-secondary chemistry. Proceedings of the $4^{\text {th }}$ Greek-Cypriot Chemistry Conference - Chemistry and Education, pp. 135-140. Ioannina: Association of Greek Chemists and University of Ioannina.

Tsaparlis G., Georgiadou A., Kafetzopoulos C., Lefkopoullou S., and Fantaki G. (2014). The new program of studies for (Greek) lower secondary education and propsed educational material. Paper presented at the $1^{\text {st }}$ Greek Conference on educational material for mathematics and science. Rhodes Greece: University of the Aegean, (Submitted for inclusion in the conference proceedings.)

Tsaparlis G. and Stergiou E. (2014). Educational material (textbook) for $11^{\text {th }}$ grade chemistry on the basis of connection of the course with life and applications. Paper presented at the $1^{\text {st }}$ Greek Conference on educational material for mathematics and science. Rhodes Greece: University of the Aegean, (Submitted for inclusion in the conference proceedings.) 